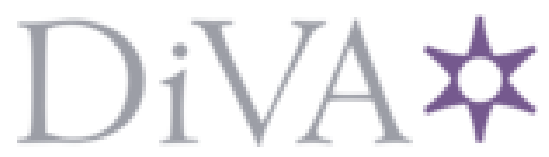

http://www.diva-portal.org

\title{
Postprint
}

This is the accepted version of a paper published in Biomedical microdevices (Print). This paper has been peer-reviewed but does not include the final publisher proof-corrections or journal pagination.

Citation for the original published paper (version of record):

Chu, J., Undin, T., Lind, S., Hjort, K., Dahlin, A. (2015)

Influence of surface modification and static pressure on microdialysis protein extractionefficiency.

Biomedical microdevices (Print)

http://dx.doi.org/10.1007/s10544-015-0005-3

Access to the published version may require subscription.

N.B. When citing this work, cite the original published paper.

Permanent link to this version:

http://urn.kb.se/resolve?urn=urn:nbn:se:uu:diva-261031 


\section{Influence of surface modification and static pressure on microdialysis protein extraction efficiency}

Jiangtao $\mathrm{Chu}^{1}{ }^{*}$, Torgny Undin ${ }^{2}$, Sara Bergström Lind ${ }^{2}$, Klas Hjort $^{1}$ and Andreas P. Dahlin ${ }^{1}$

${ }^{1}$ Department of Engineering Sciences, Uppsala University, Box 534, SE-751 21 Uppsala, Sweden.

${ }^{2}$ Department of Chemistry-BMC, Analytical Chemistry and Science for Life Laboratory, Uppsala University, Box 599, SE-751 24 Uppsala, Sweden.

* Correspondence to:

Jiangtao Chu, Department of Engineering Sciences, Uppsala University, Box 534, SE-751 21

Uppsala, Sweden.

Email: jiangtao.chu@angstrom.uu.se

Telephone: +46184713010

Klas Hjort, Department of Engineering Sciences, Uppsala University, Box 534, SE-751 21

Uppsala, Sweden.

Email: klas.hjort@angstrom.uu.se

Telephone: +46184713141

Page $\mid 1$ 


\section{ABSTRACT}

There is growing interest in using microdialysis (MD) for monitoring larger and more complex molecules such as neuropeptides and proteins. This promotes the use of MD membranes with molecular weight cut off (MWCO) of $100 \mathrm{kDa}$ or above. The hydrodynamic property of the membrane goes to ultrafiltration or beyond, making the MD catheters more sensitive to pressure. In the meantime, despite the large pore size, studies have shown that membrane biofouling still lead to unstable catheter performance. The objective is to study in vitro how $500 \mathrm{kDa}$ dextran and Poloxamer 407 surface modification affect the fluid recovery (FR) and extraction efficiency (EE) of $100 \mathrm{kDa}$ MWCO MD catheters. A pressure chamber was designed to facilitate the tests, using as MD sample a protein standard with similar concentrations as in human cerebral spinal fluid, comparing native and Poloxamer 407 modified MD catheters. The collected dialysate fractions were examined for FR and protein EE, employing Dot-it Spot-it Protein Assay for total protein EE and targeted mass spectrometry (MS) for EE of individual proteins and peptides. The FR results suggested that the surface modified catheters were less sensitive to the pressure and provide higher precision, and provided a FR closer to $100 \%$. The surface modification did not show a significant effect on the protein EE. The average total protein EE of surface modified catheters was slightly higher than that of the native ones. The MS EE data of individual proteins showed a clear trend of complex response in EE with pressure.

Keywords: microdialysis, surface modification, poloxamer, protein, extraction efficiency 


\section{INTRODUCTION}

Microdialysis (MD) is a sampling technique that uses a hollow fiber dialysis or ultrafiltration membrane to collect time resolved samples from the area of interest (Ungerstedt 1991; Chaurasia 1999; Plock and Kloft 2005). MD is well established as a clinical sampling tool for monitoring small hydrophilic molecules such as lactate, puruvate and glucose in neurointensive care settings (Hillered et al. 2005; Helmy et al. 2007). There is a growing interest in monitoring larger and more complicated molecules such as neuropeptides (Rosdahl et al. 2000; Dahlin et al. 2004; Schutte et al. 2004), cytokines (Ao and Stenken 2006) and proteins (Kjellstrom et al. 1999; Clough et al. 2007; Dahlin et al. 2010). Monitoring larger molecules requires ultra-filtration or microfiltration membranes with molecular weight cut off (MWCO) of $100 \mathrm{kDa}$ or above. The large pore size affect the hydrodynamic equilibrium in the catheter by making it more sensitive to pressure changes exerted by static, osmotic and dynamic pressures (Chu et al. 2014a). It is therefore important to tune in the MD system in order to obtain near $100 \%$ fluid recovery (FR) and thereby avoiding leakage, or drainage of, the surrounding sampling environment. (Chu et al. 2014b). FR is defined as the ratio between perfusate pumped into the catheter and the collected fraction volume and is linearly proportional to the applied static sample pressure (Chu et al. 2014a). The trans-membrane osmotic pressure and MD perfusion fluid flow rate affect the rate of the linear increase of FR with raised static pressure (Chu et al. 2014a). The most common way of adjusting FR is by adding albumin (Helmy et al. 2009) or large dextran molecules (60-500 kDa)

(Dahlin et al. 2010; Dahlin et al. 2014; Chu et al. 2014a) to the perfusion fluid. Extraction efficiency (EE, a.k.a. relative recovery) is the concentration ratio between the analyte in the collected MD fraction and the analyte in the sample where the membrane is placed. However, albumin rules out consecutive proteomic applications using liquid chromatography (LC) in Page $\mid 3$ 
combination with mass spectrometry (MS) based detection since the added albumin would completely dominate the sample loading. Albumin will also diffuse through a $100 \mathrm{kDa}$ membrane, mix into the tissue and contaminate the sample environment. Compared to albumin, dextrans of higher MWs will not diffuse through a $100 \mathrm{kDa}$ membrane and are compatible with LC/MS (Rosenbloom et al. 2005).

Another challenge to consider when sampling proteins with MD is its intrusive interaction with the organism. The MD catheter will cause irritation and often an inflammatory response, which will change the biological sampling environment. The reason for this reaction is the well-known protein adsorption process to foreign material that eventually leads to biofouling and encapsulation (Geoffrey et al. 2014). This is a severe problem in MD since it alters the pore size of the membrane and also initiates response actions that make result interpretation more complicated (Geoffrey et al. 2014; Wetterhall et al. 2014). Recently our group presented an approach to decrease the protein adsorption onto the MD catheter (Dahlin et al 2010). The catheters were soaked in a 5\% (w/v) solution containing the triblock co-polymer, Poloxamer 407 (a.k.a. Pluronic F-127) prior to MD-sampling. The polymer consists of one hydrophobic polypropylene oxide (PPO) group flanked by two hydrophilic polyethylene oxide (PEO) strands. The triblock co-polymer forms a cilia-like brush layer of PEO strands on the surface of the hydrophobic membrane and tubing of the MD catheter (Currie 2003). The Poloxamer 407 coated MD-membranes adsorbed 33\% less proteins than membranes without coating (Dahlin et al. 2012). The coating has shown to increase the FR precision both in vitro (Dahlin et al. 2010) and in vivo (Dahlin et al. 2014).

Combined use of $500 \mathrm{kDa}$ dextran in the perfusate and Poloxamer 407 coated MD catheters has indicated more consistent and responsive EE in vivo, when tested in porcine brain injury model (Dahlin et al. 2014). The objective of this in vitro study is to further investigate how $500 \mathrm{kDa}$ Page | 4 
dextran and Poloxamer 407 coated MD catheters affect the FR and EE, under a pressurized sampling setting.

\section{EXPERIMENTAL METHODS}

\subsection{Chemicals}

The perfusion fluid was based on a Ringer's solution of $147 \mathrm{mM} \mathrm{NaCl}, 2.7 \mathrm{mM} \mathrm{KCl}, 1.2 \mathrm{mM}$ $\mathrm{CaCl}_{2}$ and $0.85 \mathrm{mM} \mathrm{MgCl}$, prepared in house. Acetonitrile (ACN), acetic acid (HAc) and ammonium-di-hydrogen phosphate $\left(\mathrm{NH}_{4} \mathrm{H}_{2} \mathrm{PO}_{4}\right)$ were obtained from Merck (Darmstadt, Germany). Dextran T500 (average molecular weight $500 \mathrm{kDa}$, batch no. HE518) was purchased from Pharmacosmos (Holbaek, Denmark) and used to prepare a 3\% Dextran T500 (w/v) colloid Ringer's solution. Deionized water (DI) was produced in-house. Iodoacetamide (IAA), ammonium bicarbonate $\left(\mathrm{NH}_{4} \mathrm{HCO}_{3}\right)$, dithiothreitol (DTT), Poloxamer 407 and all proteins and neuropeptides (Table 1) were obtained from Sigma-Aldrich (St. Louis, MO, USA). Trypsin was of sequence-grade from Roche Diagnostics (Basel, Switzerland).

Five proteins and two peptides were blended in an acetate buffered Ringer's solution ( $\mathrm{pH} 7.4)$ and used as sampling matrix. The content and concentration of the proteins and peptides standard are listed in Table 1. The standard is made with similar concentration as of the human cerebral spinal fluid with a total protein concentration of $392.5 \mu \mathrm{g} / \mathrm{mL}$. After the protein matrix was made, it was fractionated and stored in a $-20^{\circ} \mathrm{C}$ freezer. Before the experiment, one protein fraction was allowed in room temperature to slowly thaw.

\subsection{The in vitro test chamber}

Page $\mid 5$ 
Compared to the in vitro pressure chamber used in a previous study by Chu et al. (2014a), the test chamber in this study used similar pressurization principle but a different design. The test chamber was constructed by modifying a standard $5 \mathrm{~mL}$ test bottle made of glass and a plastic cap. Six holes were drilled through the cap. The diameters of the holes were chosen to fit polytetrafluoroethylene (PTFE) tubes. The dimensions of the test bottle with its tubes and their positions on the cap are shown in Fig. 1.

Four holes on the periphery of the cap were fitted with four tubes, which are used to introduce the MD catheters into the chamber. The hole in the centre of the cap was fitted with a tube leading to a pressure sensor. The last tube was inserted through the sixth hole, which was used for sample injection and reached down to nearly the bottom of the bottle. The four MD catheter introduction tubes were protruded $10 \mathrm{~mm}$ into the cap, the pressure sensor tube was protruded 2 $\mathrm{mm}$ in depth, and the sample injection tube was protruded $32 \mathrm{~mm}$ in depth. The tubes were firmly fixed and glued onto the cap, with no leakage.

The four MD catheter introduction tubes have Luer-lock mechanism on their open end, which fits with the counter-part on the CMA71 MD catheter. Hence, when the MD catheters were inserted and fitted into the introduction tubes, air tight condition was achieved and the positions of the catheters in the test chamber were fixed as well. The centres of the MD catheter membranes were positioned with $5 \mathrm{~mm}$ distance between each other, $19 \mathrm{~mm}$ down from the cap and into the chamber (the total depth of the chamber is $40 \mathrm{~mm}$ ), Fig. 1.

\subsection{Microdialysis in vitro experiment set-up}

Four MD catheters of model CMA71 (10 mm membrane length, $100 \mathrm{kDa}$ MWCO, outlet tubing length $220 \mathrm{~mm}$ and inner diameter $1.5 \mathrm{~mm}$; CMA Microdialysis, Solna, Sweden) were used in each experiment. A CMA400 syringe pump (CMA Microdialysis, Solna, Sweden) was used to Page $\mid 6$ 
deliver the perfusion fluid with a flow rate of $1 \mu \mathrm{L} / \mathrm{min}$. The pressurization of the chamber was achieved by a syringe pump, which presses MD test sample into the chamber through the liquid injection tube, Fig. 1. The liquid injection constitutes of a Hamilton gastight $10 \mathrm{~mL}$ syringe (model 1010RN, Hamilton Bonaduz AG, Bonaduz, Switzerland) with a EFD Precision tip (model 5114-0.25-B, Verick International, Brampton, Ontario, USA). The tip was connected to the PTFE liquid injection tube using a silica tubing of $2 \mathrm{~mm}$ length. The liquid injection syringe was mounted onto a Harvard PhD 2000 infusion syringe pump (Harvard apparatus, Holliston, MA, USA).

A Digitron 2081P manometer (Digitron instrumentation Ltd, Devon, England) was used as the pressure sensor to monitor the chamber pressure. The measuring portal of the manometer was connected to a section of $438 \mathrm{~mm}$ long silica tube which has an inner diameter of $2.9 \mathrm{~mm}$. The silica tube was then connected with the PTFE pressure tube on the chamber cap. The reading of the manometer was the measured air pressure subtracted by atmospheric pressure.

\subsection{Microdialysis surface modification}

The surface modification of the MD catheter was performed by a dynamic surface modification process with Poloxamer 407 (Dahlin et al 2010). Briefly, MD catheters were coated at room temperature by continuously perfuse the catheters with 5\% w/v Poloxamer 407 solution with a flow rate of $0.5 \mu \mathrm{L} / \mathrm{min}$ for $24 \mathrm{~h}$. The catheters were placed in 5\% w/v Poloxamer 407 solution to ensure modification on the outside and inside of the membranes. After the surface modification, the catheters were washed with water for $12 \mathrm{~h}$.

\subsection{Microdialysis test protocols}

Prior to the MD sampling, four MD catheters were inserted into the chamber. Then MD test Page $\mid 7$ 
sample (the protein and peptide standard, content and concentration were shown in Table 1) which slowly thaw under room temperature and reached $23^{\circ} \mathrm{C}$, was injected into the chamber by the $10 \mathrm{~mL}$ Hamilton syringe to completely fill the chamber, while in the meantime the pressure sensing channel was kept open to air, to allow excess air to be removed from the chamber. After the chamber was filled with sample, the pressure tube was connected with the pressure sensor and the chamber was sealed.

The whole chamber was immersed into a temperature control water bath (Lauda Dr. R. Wobser GMBH \& CO., Lauda-Königshofen, Germany), to keep the chamber temperature at $37.5^{\circ} \mathrm{C}$.

Prior to the insertion of the MD catheters into the chamber, the catheters were flushed in DI water using Ringer's solution as perfusion fluid, at flow rate of $15 \mu \mathrm{L} / \mathrm{min}$. During the test, the perfusion fluid in the MD catheters is Ringer's solution blended with 3\% (w/v) Dextran T500. The protein standard is the MD test sample. The MD perfusion rate was $1 \mu \mathrm{L} / \mathrm{min}$, for all tests. Before collection of dialysate fractions, the MD catheters were firstly flushed with perfusate using a flow rate of $15 \mu \mathrm{L} / \mathrm{min}$ for 5 minutes, followed by 15 minutes equilibration time at 1 $\mu \mathrm{L} / \mathrm{min}$. Then the dialysate collection began.

Pressurization of the chamber was conducted by injecting the MD test sample into the chamber at various flow rates. The pressurization injection rates were adjusted during the test, to achieve three samples at similar chamber pressure in a close ranges. During the test, the chamber pressure was recorded every second by the pressure sensor. The average pressure during each test was used to represent the chamber pressure for that test, Table S1.

Dialysate fractions were collected in pre-weighted micro vials, which were positioned at the same height as the MD catheter centre position. After each test, which took about 90-140 minutes, the micro vials were weighed to get the volume of the collected dialysate. A dialysate fraction volume, ranging from 80 to $150 \mu \mathrm{L}$, was collected from individual MD catheter. After Page $\mid 8$ 
collection, the micro vials were stored in a freezer at $-20{ }^{\circ} \mathrm{C}$.

The MD dialysate collection details are listed in Table S1. For each test set (e.g., Native No.1-4, Poloxamer 407 No.1-4), three tests were done at a certain pressure level. Four of such test sets were done for native and Poloxamer 407 coated MD catheters, respectively. In total, 12 samples each (four pressures times three repeat) were conducted with the four native MD catheters, and 12 samples each with the four Poloxamer 407 modified catheters. In total 96 dialysate fractions were collected. The Poloxamer 407 and the native test sets used the same perfusion fluid, protein standard, and perfusion flow rate, with only slight variations in the pressure ranges. Table S1 shows the test set in time sequence of experiment.

In the first test set both for native and Poloxamer 407 modified catheters, the pressurization injection rate started with zero, which means that there were none MD sample injections from the pressurization syringe into the chamber so the chamber pressure is equal to atmospheric pressure. After that, the pressure ranges were chosen to follow the 10-7-15 torr order for native and 5-10-20 torr for Poloxamer 407, as shown in Table S1. The pressure sequences were set random (after the first test set, for native and Poloxamer 407 modified catheters, respectively), to avoid any potential effect that a gradually increased or decreased pressure in sequence would bring in slight difference on the catheter sampling performance in statistical level.

\subsection{Dot-it Spot-it ${ }^{\circledR}$ Protein Assay}

Dot-it Spot-it@ Protein Assay (Maplestone AB, Knivsta, Sweden) was used to analyse the total protein concentration for each collected MD dialysate fraction.

For the protein assay, $15 \mu \mathrm{L}$ of the collected dialysate fractions from each single test (in total 96 dialysates, 48 each for Native and Poloxamer 407 test) were mixed with a solution of the 
detergent sodium dodecyle sulfate (SDS), to produce $20 \mu \mathrm{L}$ of protein assay test sample containing $0.5 \%$ SDS.

The standard Dot-it-Spot-it® Protein Assay experimental procedures were followed (Lönnberg et al. 2015), except the modification of the protocol by decreasing SDS amount from $1 \%$ to $0.5 \%$. The aim of this modification was to optimize for the protein concentration analysis of our dialysates which contain dextran.

\subsection{Sample preparation for mass spectrometry}

The MD dialysates were first dried under vacuum. All samples were re-dissolved in $200 \mu \mathrm{L}$ of $0.1 \mathrm{M} \mathrm{NH}_{4} \mathrm{HCO}_{3}$. The disulfide bridges in the proteins were reduced by adding $10 \mu \mathrm{L}$ of $45 \mathrm{mM}$ DTT and incubation for $15 \mathrm{~min}$ at $50{ }^{\circ} \mathrm{C}$. This was followed by alkylation of the cysteines by adding $10 \mu \mathrm{L}$ of $100 \mathrm{mM}$ IAA and keeping the samples at room temperature for $15 \mathrm{~min}$ in darkness. The samples were enzymatically digested by adding $1 \mu \mathrm{g}$ trypsin and the digestion was carried out over night at $37{ }^{\circ} \mathrm{C}$. After the digestion, the microdialysates were dried by vacuum centrifugation and re-dissolved in $200 \mu \mathrm{L}$ of $2.5 \%$ acetic acid and desalted on a Isolute C18(EC)

(1 mL, $50 \mathrm{mg}$ capacity, Biotage, Uppsala, Sweden) SPE column using the following schedule: The column was first wetted in $1 \mathrm{~mL} 100 \%$ acetonitrile and equilibrated with $5 \times 1 \mathrm{~mL} 1 \%$ acetic acid. The tryptic peptides were adsorbed to the media using 3 repeated cycles of sample loading by collecting the sample eluent and reapplying it on the top of the SPE column. The column was washed using $3 \times 1 \mathrm{~mL}$ of $1 \%$ acetic acid and finally the peptides were eluted in $250 \mu \mathrm{L} 50 \%$ acetonitrile, $1 \%$ acetic acid. After desalting, the eluate was vacuum centrifuged to dryness. Prior to nanoflow LC-MS analysis, the peptides were re-dissolved in $100 \mu \mathrm{L}$ of $0.1 \% \mathrm{HAc}$.

\subsection{Mass spectrometry}

Page $\mid 10$ 
The MS analysis was performed according to a method recently developed in our group (Undin 2015). Briefly, an LTQ Orbitrap Velos Pro Mass spectrometer (ThermoFisher Scientific, Bremen, Germany) was used to aquire mass data. The MS was equipped with a nano-electrospray ionization (ESI) ion source and operated in positive ion mode. The liquid chromatography separation was carried out using a Thermo Easy-nano Liquid Chromatography II instrument (ThermoFisher Scientific, Bremen, Germany).The sample injection volume was $5 \mu \mathrm{L}$ and the column system consisted of a pre-column of $2 \mathrm{~cm} x$ $100 \mu \mathrm{m} \mathrm{C}_{18}$-A1 (length $\mathrm{x}$ internal diameter), $5 \mu \mathrm{m}$ particles $120 \AA$ pore size and an analytical column of $10 \mathrm{~cm} \times 75 \mu \mathrm{m}, \mathrm{C}_{18}-\mathrm{A} 2$ column with a particle size of $3 \mu \mathrm{m}$ particle size and $120 \AA$ pore size (Easy columns, ThermoFisher Scientific, Bremen, Germany). The liquid phase was a $\mathrm{H}_{2} \mathrm{O}$ :ACN:acetic acid solvent system $\left(\mathrm{H}_{2} \mathrm{O}, 0.1 \%\right.$ FA mobile phase [A]; ACN, 0.1\% FA mobile phase [B]). A flow rate of $0.3 \mu \mathrm{L} / \mathrm{min}$ was applied, starting with isocratic elution at $2 \% \mathrm{~B}$ for $2 \mathrm{~min}$, followed by gradient elution from $3 \%$ to $45 \% \mathrm{~B}$ during $15 \mathrm{~min}$, and then from $45 \%$ to $80 \%$ B within 3 min, and finally $80 \%$ B for 15 min. Firstly a modified single ion monitoring (SIM) scan was performed in Fourier Transform (FT) cell recording a window between 400 and $650 \mathrm{~m} / \mathrm{z}$ with a resolution of 30,000 to detect the peptide ions. Thereafter, a collision induced dissociation (CID) MS/MS experiment of the most intense ion in the mass range, and occuring on a global inclusion list, detected in the ion trap using the following parameters. Mass witdh: $2 \mathrm{~m} / \mathrm{z}$, resolution: 7,500, normalized collision energy: 35 and activation time $10 \mathrm{~ms}$. These two steps where then repeated for mass ranges $650-850 \mathrm{~m} / \mathrm{z}$ and $850-1070 \mathrm{~m} / \mathrm{z}$.

Acquired data (.raw-files) was imported into Proteome Discoverer (version: 1.4.0.288) where protein identificationwas performed using the internal Sequest-HT search engine against a FASTA-file containing the proteins in the protein mix. The search parameters were set to Page | 11 
enzyme: Trypsin, fixed modifications: carbamidomethylation (C), variable modifications: oxidation(M), deamidation( $\mathrm{N}, \mathrm{Q})$, peptide mass tolerance: $\pm 0.02 \mathrm{Da}$, fragment mass tolerance: $\pm 0.7 \mathrm{Da}$, maximum missed cleavages $=0$ Proteins were only considered to be positively matched if they passed the scoring $(\mathrm{p} \leq 0.05)$ of the target decoy PSM validator.

\subsection{Data analysis}

PinPoint (ThermoFisher Scientific) and Skyline (Maclean et al. 2010) for evaluation of targeted quantification were used. The quantification was based on the chromatographic peak areas recorded in the SIM scans of selected peptides from the proteins of interest. Final quantification at the protein level was performed using 2-3 selected peptides per protein. The response of the peptides was related to a calibration curve using a calibration curve based on a dilution series of the analysed standard. The averaged corresponding concentrations observed for the peptides were reported as the protein concentration.

\section{RESULTS AND DISCUSSION}

This study resulted in a new chamber design for in vitro MD tests, Fig. 1. Also, there are three kinds of original data in this study: FR, total protein concentration (later converted to total EE), and the relative concentrations of each peptide and protein (in the protein standard, two peptides and five proteins).

The FR data originated from the volume ratio dialysate/perfusion fluid, for 96 dialysate fractions, Fig. 2. There is a total protein concentration data for each of 96 dialysate fractions as well, which was converted to total EE by taking its ratio to the concentration of protein standard, Fig. 3. 
The MS result gives the relative concentration with respect to the original standard, for each protein and peptide under different chamber pressures, Fig. 4.

Furthermore, all the data points from FR, total protein concentration and MS have been put together and analysed with the Principle Component Analysis (PCA) method, to statistically explore the relations between the MD factors, Fig. 5.

\subsection{Design features of the in vitro test chamber}

The in vitro test chamber in this work followed the same pressurization principle as the in vitro chamber in the previous study of Chu et al. (2014a). The chamber was validated air tight by the pressure being maintained for a long time after raising the chamber pressure. Since the design and material of the in-vitro chamber in this work is much different from the previous chamber (Chu et al. 2014a) , it has the following advantages compared to the previous chamber:

1- The smaller chamber volume requires less sample and the smaller size reduces the potential fluid flux and turbulence compared to the previous test chamber.

2- The four catheters have similar and closer sampling positions, which reduces the difference between them. In the previous chamber, the catheters were positioned perpendicularly to the chamber sample injection path from the injection port to the pressure sensing port, which introduced small sample concentration gradients between the four catheters. Since the catheters here are positioned parallel along the sample injection path, there is no such gradient between the four catheters. Instead all membranes are subjected to a similar diffusion pattern

3- The positioning of the injection tube reaches close to the bottom of the chamber which reduces fluid flux and injection turbulence.

Page $\mid 13$ 
4- Having the pressure sensing port on top of the chamber cap gives the advantages of: a) no dead volume of air trapped inside the chamber; and b) effective removal of the air bubbles inside the chamber during the initial sample filling.

5- Glass bottle with screw cap make the test chamber easy to assemble/dissemble. The bottle is easy to clean and re-use. The bottle and the cap are low-cost and on-shelf available with standard dimensions.

\subsection{Fluid recovery as a function of pressure and surface modification}

The FR data is plotted in Fig. 2 as a function of chamber pressure, for native and surface modified MD catheters respectively.

For native catheters, the FR increased linearly with increased chamber pressure, having a linear fit between the FR and the chamber pressure of $y=2.1 x+88\left(R^{2}=0.94\right)$. This behaviour is similar to the FR behaviour and theoretical analysis of native catheter (Chu et al. 2014a). For surface modified catheters, the linear fit was $y=1.0 x+87\left(R^{2}=0.91\right)$. At atmospheric pressure, FR of native and surface modified catheters is similar, but the increase of FR with pressure for the surface modified catheters is just half of that of the native catheters.

In alignment with previous studies (Dahlin et al. 2010; Dahlin et al. 2014), the Poloxamer 407 modified catheters have higher FR-precision compared to the native catheters. Based on the theory in the study by Dahlin et al. (2012), the Poloxamer 407 coating will alter the pore and membrane surface structure, from which the consequence may be an increased membrane resistance. An increased membrane resistance leads to a lower slope value in the linear function between FR and chamber pressure (Eq. 2(b) in Chu et al. 2014a). Since other than the coating no experimental condition has been changed, this suggests that the surface coating increased the membrane resistance. This may be due to a smaller hydraulic diameter in the membrane pores.

Page $\mid 14$ 
Comparing the similar cases of the native catheters in this study with the result of the previous study $y=2.3 x+90$ (Fig. 4 (b) in Chu et al. 2014a). With the only difference of having a low amount of proteins solved in the Ringer's solution as the MD sample for this study, the test conditions of the two tests can be considered to be similar, which is confirmed by the two linear fit equations. In Fig. 4 (c) of the previous study (Chu et al. 2014a), linear series $y=1.1 x+94.3$ represents the case of Native catheter $+3 \%$ Dextran T500 in Ringer solution as perfusate $+1 \%$ Dextran T500 in Ringer solution as MD sample $+1 \mu \mathrm{L} / \mathrm{min}$ as perfusion rate. The result in Fig.2 b) of this study represents the case of Poloxamer 407 modified catheter $+3 \%$ Dextran T500 in Ringer solution as perfusate + protein standard as MD sample $+1 \mu \mathrm{L} / \mathrm{min}$ as perfusion rate, and gives $y=1.0 x+86.7$ as previously mentioned. The similarity is on the slope value, they are close and both lower than that of the native. Another similarity is their obviously smaller deviation range compared to the native ones. The difference on the test conditions is that the former case used native catheter but 1\% Dextran T500 in Ringer solution as MD sample, where the higher osmotic pressure from the $1 \%$ dextran MD sample with respect to pure ringer solution, will reduce the inwards osmotic fluid pulling potential from the perfusate. This equals to an increased resistance on the inwards flow of the MD sample fluid. In the latter case, protein standard was used as MD sample, which is the same as Ringer solution regarding osmotic potential. That is, there was no contribution from the MD sample to the increased resistance of the inwards flow of the fluid. But still, in the latter case, the slope value decrease indicates that the fluid resistance is increased. This could only be attributed to the surface modified catheters, as it is the only different test condition left. The Poloxamer 407 coating may contribute to the reduction of the pore size because its absorption into the cave system of the pore structure, leading to an effective MWCO much smaller than the declared MWCO of the catheter. This 
means that the surface coating increased the resistance for the fluid to be collected into the catheter. Or in another word, the coating increased the membrane resistance.

In the in vivo MD sampling study of Dahlin et al. (2014), Poloxamer 407 modified catheters compared to the native catheters, the FR of Poloxamer 407 modified $100 \mathrm{kDa}$ MD catheters exhibited the same FR characteristics as this in vitro study: higher precision among individual catheters and lower sensitivity to pressure.

\subsection{Total protein extraction efficiency}

The total protein concentrations of the dialysates were measured by the Dot-it Spot-it Protein Assay and plotted with the chamber pressure, Fig. 3. If the concentration is divided by the concentration of the MD sampling matrix - the protein standard of $392.5 \mu \mathrm{g} / \mathrm{mL}$, the ratio is the total protein EE. For native catheters, the concentrations are mostly below $3 \mu \mathrm{g} / \mathrm{mL}$ (nine data points out of twelve), with three higher concentration points presented at a pressure range around 10 torr. If converted to total protein EE, the nine values are $0.2-0.7 \%$. For the surface modified catheters, six concentrations were below $3 \mu \mathrm{g} / \mathrm{mL}$ and the other six were all above $4 \mu \mathrm{g} / \mathrm{mL}$. For these six higher values, three of them occurred in the pressure range around 5 torr, and another three at 15-20 torr. The highest concentration was $8 \mu \mathrm{g} / \mathrm{mL}$, which represented a total EE of $2 \%$. The high error bars indicate that much of these variations should be due to the assay experiments, although the average protein concentration for the surface modified catheters is higher than the native ones (Fig. 3). There is no indication that the Poloxamer 407 modification increased the total protein EE on a significant level. By comparing the performance differences between native and surface modified catheters - FR for Fig. 2 and total EE for Fig. 3, they showed that the introduction of Poloxamer 407 as surface modification seems has changed the level of FR significantly, but has not affected the total EE as significantly as to the FR.

Page $\mid 16$ 
The EE values may seem to be low but are in the same range as reported Rosenblomm et al. (2005) which performed MD under similar test condition, dextran in the perfusate, $1 \mu \mathrm{L} / \mathrm{min}$ flow rate continuously sampling for several hours. Their study on the native catheters suggested that for certain proteins the EE drops drastically after a short sampling duration (Rosenblomm et al. 2005). Membrane fouling reduces the effectiveness of MD sampling, but the protein adsorption onto the MD membrane does not appear to prevent its use for sampling of small, low molecular weight molecules (Cynthia and Stenken 2014).

Furthermore, the EE of the solute is significantly compromised and reduced as the molecular weight of the analyte begins to approach approximately $25 \%$ or greater of the MD membrane MWCO (Snyder et al. 2001; Schutter et al. 2004; Cynthia and Stenken 2014). Therefore, 3,000 kDa MWCO plasmapheresis type membranes are often used (Winter et al. 2002; Clough et al. 2007).

\subsection{Extraction efficiency of different proteins and peptides}

From the MS results, trends of EE of individual proteins and peptides are presented in Fig. 4a and $4 \mathrm{~b}$. The change in EE is given as Log 2 ratio to a normalized value of the original MS data providing trend plots where the inverted ratio gets the same distance for the normalized 1:1 line, i.e., value 1 represents twice the $\mathrm{EE}$ and value -1 as half the $\mathrm{EE}$. If the $\mathrm{EE}$ would have been unaffected by the pressure, the resulting line would have had a slope of 1 . The general trend for the proteins (Fig. 4a) is that there is a sharp increase of EE with a small increase of pressure in the beginning, followed by an as sharp decrease, and then a slow increase at higher pressures. Somatostatin (Fig. 4b) follows the same trend but not Bradykinin, which instead shows an inverted trend compared to the proteins. The sampling order were randomly chosen (Table S1) and could therefore not explain the shape of the curves. It is also known that there could be large Page $\mid 17$ 
variation in EE between different probes (Galea et al. 2014) and in sampling time (Rosenbloom et al. 2005). Therefore, MD dialysate fractions from four probes and at least two sampling times were pooled into one MS-sample, meaning that a specific probe at a certain time only contributed to $8-12 \%$ of the total result. This is the reason for the lower standard deviations presented in Fig. 4 compared to Fig. 3.

The protein EE for the Poloxamer modified catheters are more consistent in pattern compared to the native catheters. A paired, two tailed T-test confirmed a significantly lower $(\mathrm{p}=0.038)$ standard deviation for the Poloxamer modified catheters compared to the native catheters. Both results are in agreement with previous in vivo study (Dahlin et al. 2014) where it was concluded that the surface modification gives more responsive and reliable protein result. We speculate that there are two competing mechanisms for the protein transport over into the membrane, e.g., an increased migration with increased FR (which promotes the protein EE) and an increased protein adhesion to the membrane with increased pressure (which reduces the protein EE). The change of the protein adhesion behaviour should be due to the change of interaction between the polymer filaments (similar to the proprietary filament for the native catheters, and the Poloxamer 407 filament for the modified catheters) on the pore surfaces of the membrane, and the proteins. This change of adhesion behaviour may happen when the protein is somewhat pressurized and skewed against the pore surface.

\subsection{Principal component analysis}

The purpose of the PCA in this study is to show the statistical relations among the main factors of this in vitro MD test: chamber pressure, FR, protein concentration, single protein/peptide recovery and the surface modification. The analysis results are presented as Fig. 5 (a) and (b). The software SIMCA (Version 13.0.0.0, Umetrics AB, Umeå, Sweden) was used to perform the Page $\mid 18$ 
PCA. The experimental data matrix was analyzed by the 'Auto-fit' function of SIMCA, which auto-fits the data matrix to a model type, using cross validation rules to determine the number of significant components. The analysis result of the data matrix in this study suggested that two significant components were determined, PC1 and PC2. The matrix was fitted to model 2 (indicated as 'M2' in SIMCA), type PCA-X, according to SIMCA. The model's $\mathrm{R}^{2} \mathrm{X}$ (cum) value is $93.5 \%$.

The score plot of the principal component PC1 versus PC2 is shown in Fig. 5 (a). These two components together describe $64.5 \%$ of the total variation in this set of samples (of which PC1 explains $41 \%$ and PC2 $23.5 \%$ of the total variation.PC3 describes $12.2 \%$ of the total variation in the sample. The major components PC1 and PC2 together can be accounted as a valid abstract of the sample matrix, presenting the major part of the underlying structure.

Their score plot in Fig. 5 (a) clearly demonstrates the clustering of samples from the surface modified MD catheters (black squares), and from the native MD catheters (white diamonds). For instance, $\mathrm{N} 1$ represents native test pressure range no.1, and there are four pressure ranges for native and Poloxamer 407 test, respectively. There are clearly eight groups of the data points (N1-N4, P1-P4), which indicates that the in vitro sampling, the subsequent protein assay and the MS were well performed with high consistency. It can be observed that the four groups N1-N4 are located closer to the centre point of the graph, than the four groups P1-P4, which suggests that the surface modified ones did have a different degree of response in the in-vitro test.

Fig. 5 (b) is the loading plot, which can be used to interpret the score plot Fig. 5 (a). It suggests that the FR, the chamber pressure, the total protein concentration in the dialysate (white stars) were affecting the single protein recovery. Whereas the coating (single white star in the centre) did not affect the protein recovery significantly, having its position being nearly in the middle of the axis. In other words, the surface modification did not significantly alter the EE in this in vitro Page | 19 
pressure MD sampling test. This should be compared with recent in vivo results of combined use of $500 \mathrm{kDa}$ dextran and Poloxamer 407 coated MD catheters, which indicated higher EE when tested in porcine brain injury model (Dahlin et al. 2014). A possible explanation is that the increased EE was rather due to the reduced irritation of the model tissue, than an intrinsic higher EE capability of the catheter after surface modification.

\section{CONCLUSIONS}

Regarding FR, the surface modified catheter is less sensitive to pressure and provides higher precision, and is more consistent on keeping a FR close to $100 \%$.

The surface modification did not have a significant effect on the protein EE. However, there is a clear trend of a complex response in EE with pressure.

We conclude that Poloxamer 407 surface modification of MD catheters provides more stable protein sampling, but issues remain with fouling and low EE when using $100 \mathrm{kDa}$ membranes.

As future perspectives, there could be many interesting projects based on the aspects of this study, for instances -the in vitro test chamber, the surface coatings or the choice of the individual protein in the MD sample matrix to be sampled and analysed.

For example, other poloxamers as surface modifications could be worthy to investigate. Different poloxamers can be chosen with different PEO strand length and differently sized PPO cores. A combination of poloxamers of different properties, as a surface coating, could be an interesting investigation.

Particular proteins and peptides were chosen for the sample matrix of this study to simulate CSF. In future study, proteins and peptides of various specific properties could be chosen to explore 
the EE behaviour of certain sample group. For instance, molecules of certain MW range, of diverse $\mathrm{pI}$ values, or of different fluidic property, etc.

Furthermore, the in vitro chamber of this study could be a useful method for simulating specific in vivo MD sampling scenarios. For example, simulation of traumatic brain injury (TBI), which involves sudden changes of pressure in a small area.

\section{ACKNOWLEDEGEMENTS}

This research was in part supported by the Uppsala Berzelii Technology Centre for Neurodiagnostics, funded by the Swedish Governmental Agency for Innovation Systems and the

Swedish Research Council Grant number P29797-1. Financial support from Åke Wiberg and Magnus Bergvall foundation (SBL) are also acknowledged. We acknowledge mDialysis and Pharmacosomos AS for sharing their knowledge and for material support and Visualize your Science for graphical assistance. This work was supported by the Science for Life Laboratory Mass Spectrometry Based Proteomics Facility in Uppsala. Data storage was obtained and supported by BILS (Bioinformatics Infrastructure for Life Sciences).

Page $\mid 21$ 


\section{Figure and Table Captions}

\section{Figure 1}

The in vitro MD experiment set-up and the configuration of the in vitro pressure chamber. The glass chamber is sealed with a plastic cap by a Luer-lock, and filled with sample. Four MD catheters can be inserted into the chamber via the holes on the cap, with parallel positions. The chamber pressurization is controlled by precise sample injection through the centre tube (coloured blue) down to the bottom of the chamber. The pressure of the air gap is monitored by a pressure sensor while the four MD catheters are sampling.

\section{Figure 2}

FR plotted with chamber pressure. The FR points of native catheters are marked as red diamond, and surface modified catheters as blue square. Protein standard (produced in house to mimic human cerebral spinal fluid) was the sampling matrix, Ringer's solution with added 3\% (w/v) Dextran T500 was used as perfusion fluid with a flow rate of $1 \mu \mathrm{L} / \mathrm{min}$. Each data point was an average from four identical MD catheters in the same test set (i.e. values of column 'FR av.' in Table. S1). There are 12 data points for native and surface modified catheters, respectively. Their linear fits were presented (dashed for native and solid for Poloxamer).

\section{Figure 3}

The total protein EE plotted with chamber pressure, for native (red diamond) and surface modified (blue square) catheters. Similar to the FR data, each EE data point was an average from four identical MD catheters in the same test set. Their average values are presented as the horizontal lines (dashed for native and solid for Poloxamer). For native, only upside of the standard deviation bar is shown. For surface modified, only the downside is shown. Page $\mid 22$ 


\section{Figure 4}

EE of (a) proteins and (b) peptides from the MD dialysates in response to the chamber pressure, for native (dashed line) and surface modified (solid line). The EE value is the Log 2 ratio of the concentration data from the MS measurement (after normalization). Each data point is the average of three MS runs (only two runs for native first sample) on the same MS sample (each represents certain pressure). The four data points are fitted to a line to show any trend.

\section{Figure 5}

(a) Score plot from PCA analysis on the MS EE data of all proteins and peptides. The score plot is PC1 versus PC2 with surface modified (black square) and native (white diamond) MD catheters. Each point represents a MS run (11/12 for native and surface modified respectively, as stated also in Fig.4). For instance, 'N3-2' is for native MS sample no.3, the second MS run for repetition. The four MS samples N1 to N4 and P1 to P4 follow a pressure increase. The ellipse corresponds to an area with a $95 \%$ confidence interval.

(b) The corresponding loading plot of PC1 vs PC2 to the score plot, from the PCA analysis. The black squares represent proteins and two black circles represent two peptides found in the dialysate fraction, the white stars represent the test factors (coating, pressure) and the test results (Fluid recovery, total protein concentration). 
Table

Table 1

List of the proteins and peptides in the protein standard used in this study.

Page $\mid 24$ 


\section{REFERENCES}

X.P. Ao, J.A. Stenken, Methods 38, 331-341 (2006)

C.S. Chaurasia, Biomed. Chromatogr. 13, 317-332 (1999)

J.T. Chu, K. Hjort, A. Larsson, A.P. Dahlin, Biomed. Microdevices. 16, 301-310 (2014)

J.T. Chu, V. Koudriavtsev, K. Hjort, A.P. Dahlin, Anal. Bioanal. Chem. 406 (29), 7601-7609 (2014)

G.F. Clough, C.F. Jackson, J.J.P. Lee, S.C. Jamal, M.K. Church, J. Invest. Dermatol. 127, 2799-2806 (2007)

E.P.K. Currie, Advances in colloid and interface science 100-102, 205-265 (2003)

R.S. Cynthia, J.A. Stenken, Euro. J. Pharma. Sci. 57, 74-86 (2014)

A.P. Dahlin, A. Amirkhani, B. Arvidsson, K. Markides, J. Bergquist, Anal. Chem. 76, $1678-1682(2004)$

A.P. Dahlin, M. Wetterhall, K.D. Caldwell, A. Larsson, J. Bergquist, L. Hillered, K. Hjort, Anal. Chem. 82, 4376-4385 (2010) 
A.P. Dahlin, K. Hjort, L. Hillered, M.O. Sjodin, J. Bergquist, M. Wetterhall. Anal. Bioanal. Chem. 402(6), 2057-2067 (2012)

A.P. Dahlin, K. Purins, F. Clausen, J.T. Chu, A. Sedigh, T. Lorant, Anal. Chem. 86(17), $8671-8679(2014)$

J.P. Galea, P.J. Tyrrell, H.P. Patel, A. Vail, A.T. King, S.J. Hopkins, Physiological Measurement 35(3), N21-N28 (2014)

D.K. Geoffrey, M.D. Jeannine, A.S. Julie, Euro. J. Pharma. Sci. 57, 60-67 (2014)

A. Helmy, K.L. Carpenter, P.J. Hutchinson, Curr. Med. Chem. 14, 1525-1537 (2007)

A. Helmy, K.L.H. Carpenter, J.N. Skepper, P.J. Kirkpatrick, J.D. Pickard, P.J. Hutchinson, J. Neurotraum. 26, 549-561 (2009)

L. Hillered, P. Vespa, D. Hovda, J. Neurotraum. 22, 3-41 (2005)

G.D. Keeler, J.M. Durdik, J.A. Stenken, Eur. J. Pharm. Sci. 57, 60-67 (2014)

S. Kjellstrom, N. Appels, M. Ohlrogge, T. Laurell, G. Marko-Varga, Chromatographia 50, 539-546 (1999)

Page $\mid 26$ 
M. Lönnberg, The standard Dot-it-Spot-it@ Protein Assay experimental procedures. (Maplestone AB, 2015), http://dot-it-spot-it.com/method/ . Accessed 01 February 2015

B. MacLean, D.M. Tomazela, N. Shulman, M. Chambers, G.L. Finney, B. Frewen, R. Kern, D.L. Tabb, D.C. Liebler, M.J. MacCoss. Bioinformatics 26 (7), 966-968 (2010)

N. Plock, C. Kloft, Eur. J. Pharm. Sci. 25, 1-24 (2005)

H. Rosdahl, K. Hamrin, U. Ungerstedt, J. Henriksson, Int. J. Biol. Macromol. 28, 69-73 (2000)

A.J. Rosenbloom, D.M. Sipe, V.W. Weedn, J. Neurosci. Meth. 148, 147-153 (2005)

R.J. Schutte, S.A. Oshodi, W.M. Reichert, Anal. Chem. 76, 6058-6063 (2004)

K.L. Snyder, C.E. Nathan, A.Yee, J.A. Stenken, Analyst 126, 1261-1268 (2001)

T. Undin, Characterization of Molecular Adsorption Using Liquid Chromatography and Mass Spectrometry, Digital Comprehensive Summaries of Uppsala Dissertations from the Faculty of Science and Technology, (Acta Universitatis Upsaliensis, 2015, 1248. 50 pp), ISBN 978-91-554-9235-9

U. Ungerstedt, J. Intern. Med. 230, 365-373 (1991) 
M. Wetterhall, J. Bergquist, L. Hillered, K. Hjort, A.P. Dahlin, Eur. J. Pharm. Sci. 57, 34-40 (2014)

C.D. Winter, F. Iannotti, A.K. Pringle, C. Trikkas, G.F. Clough, M.K. Church, J. Neurosci. Methods 119, 45-50 (2002) 


\section{Tables}

Table 1

\begin{tabular}{lrrr} 
& MW & pI & $\begin{array}{r}\text { Concentration } \\
(\mu \mathrm{g} / \mathrm{mL})\end{array}$ \\
\hline Bradykinin & 1060 & 12.0 & 1 \\
Somatostatin & 1637 & 5.6 & 1 \\
\hline Transthyretin & 13761 & 5.31 & 2.5 \\
Serum albumin & 66472 & 5.67 & 313 \\
Serotransferrin & 77064 & 6.70 & 35 \\
Alpha-2-macroglobulin & 160809 & 5.98 & 5 \\
IgG & 150000 & & 35
\end{tabular}

Page $\mid 29$ 
Figures

Figure 1

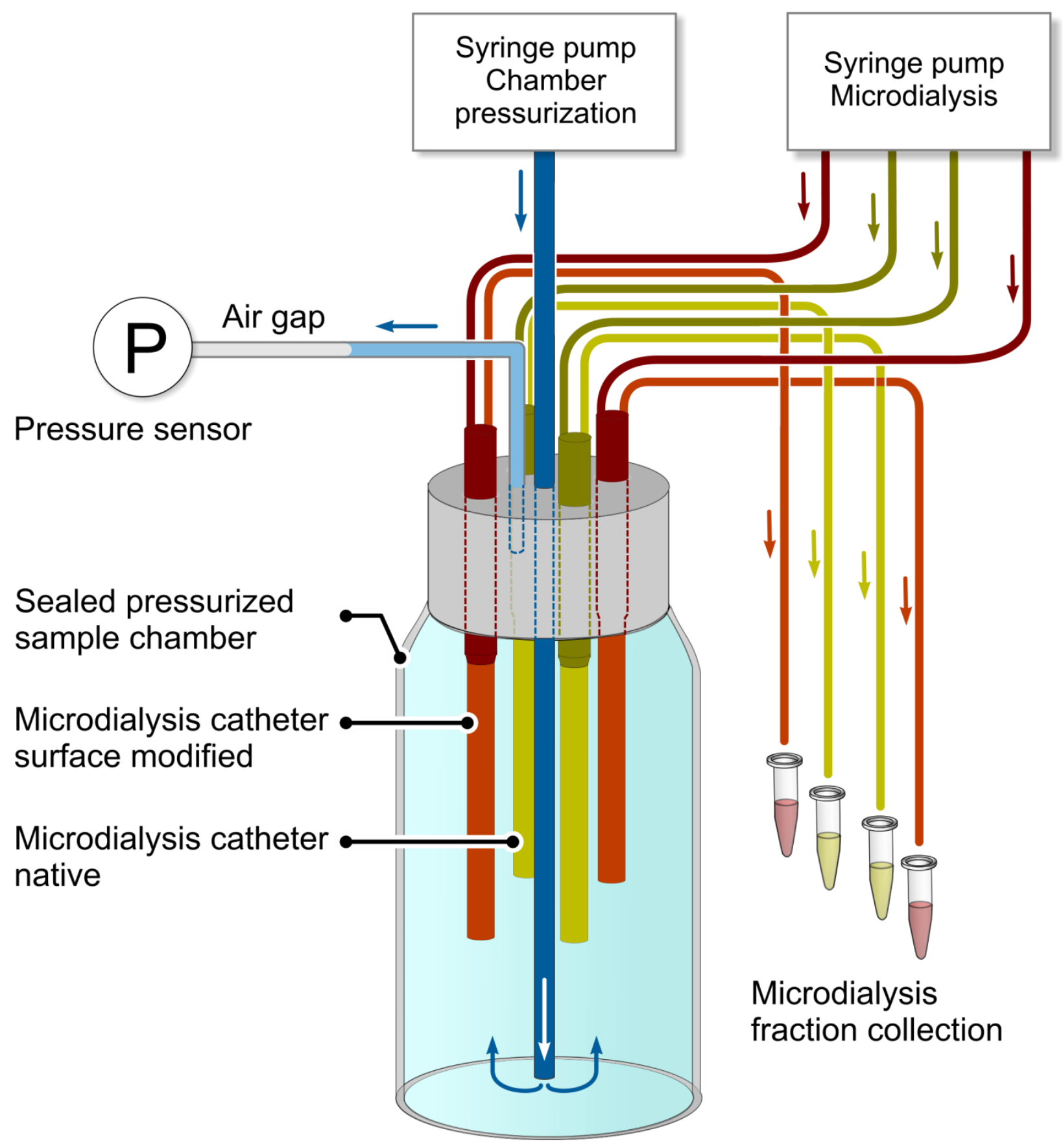


Figure 2

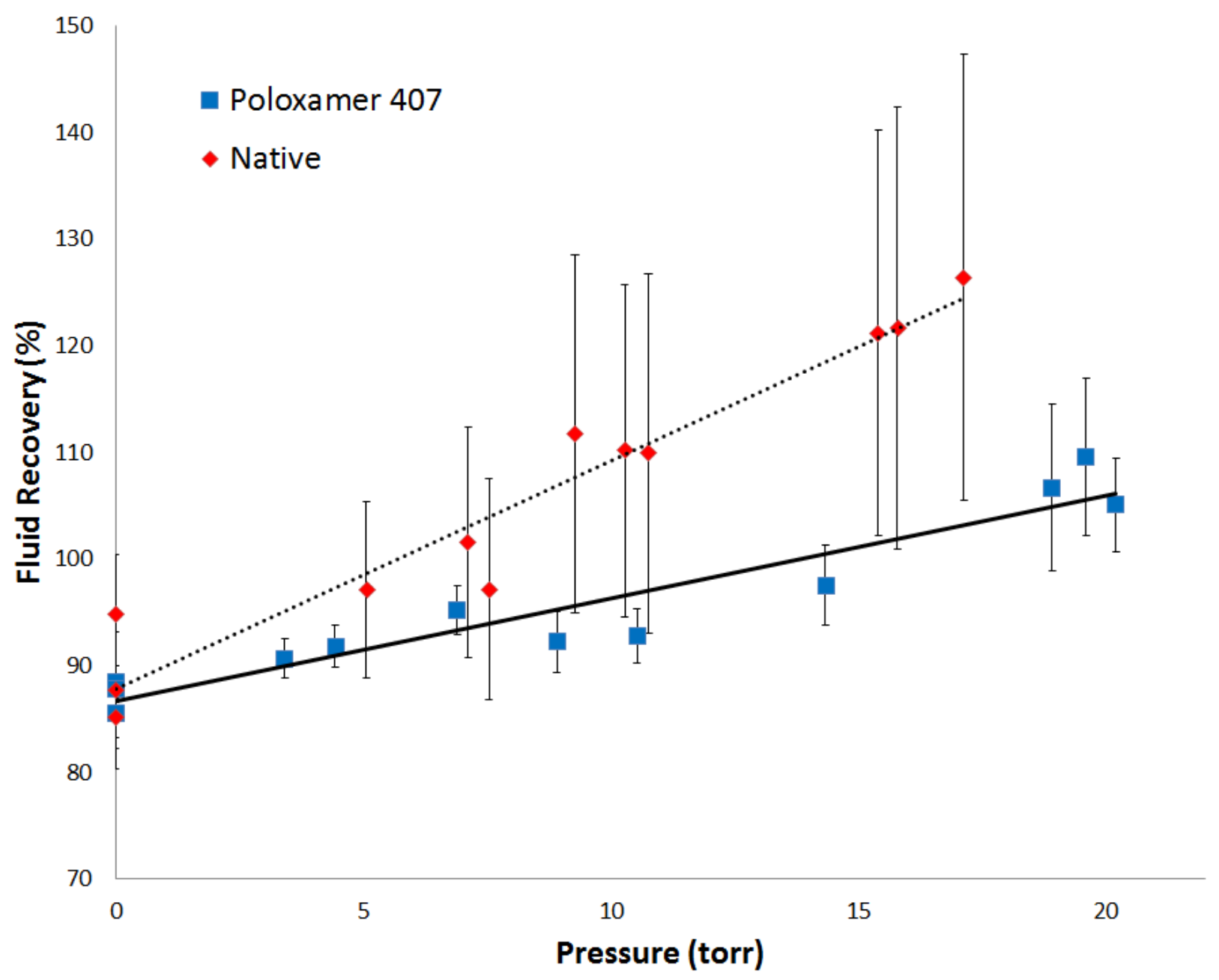

Page | 31 
Figure 3

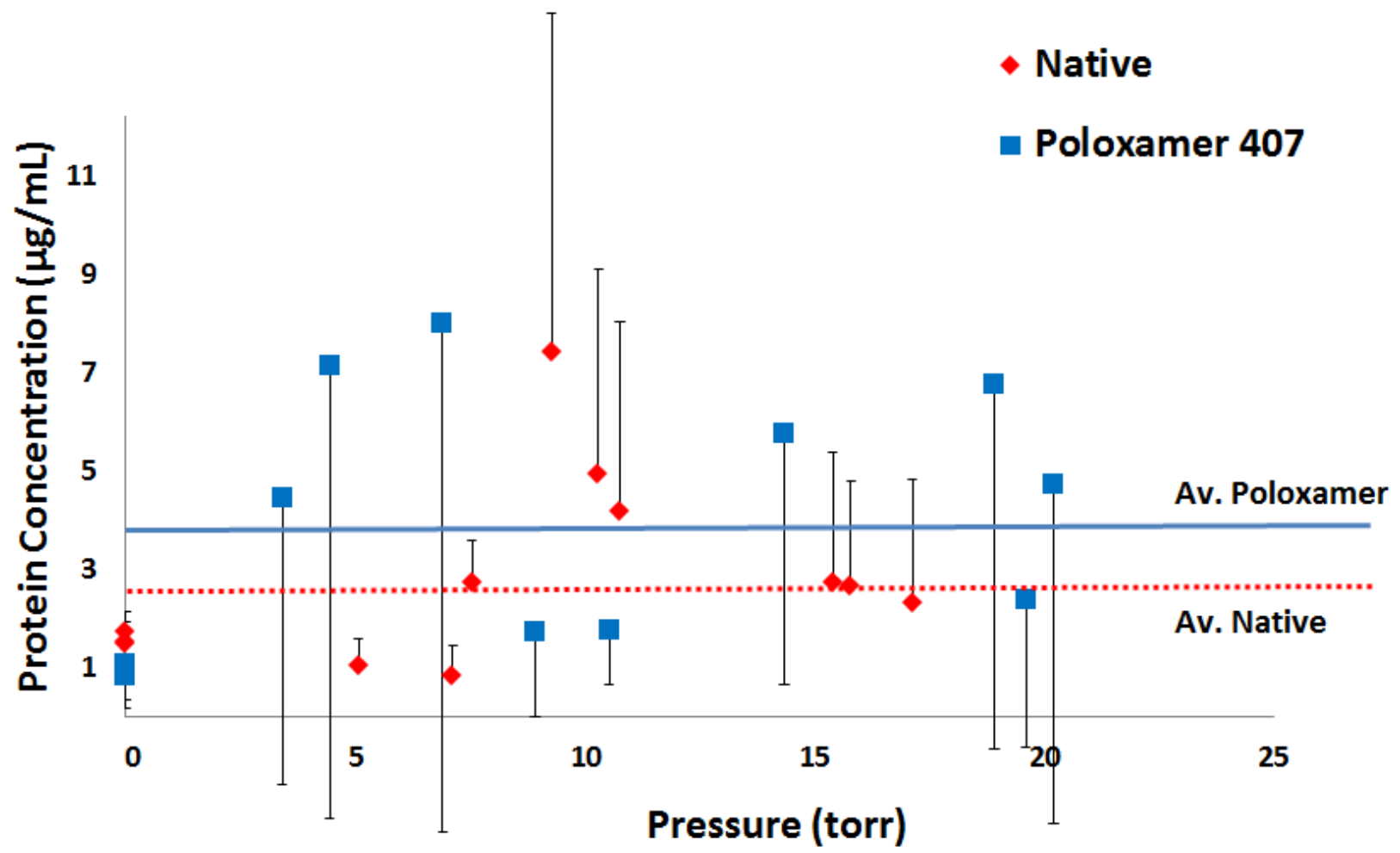

Page | 32 


\section{Figure 4}

\section{a) Proteins}
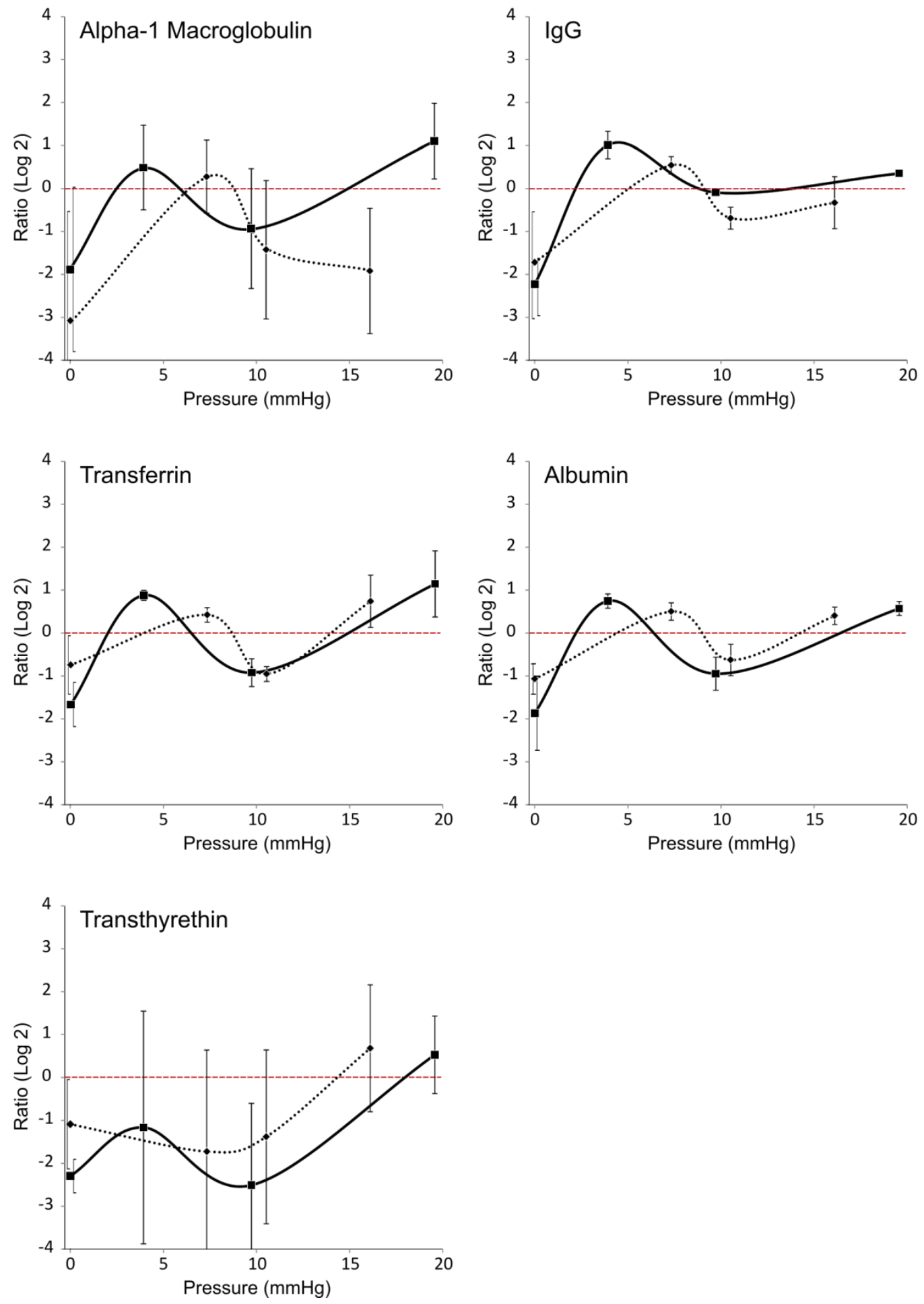

Page | 33 


\section{b) Peptides}
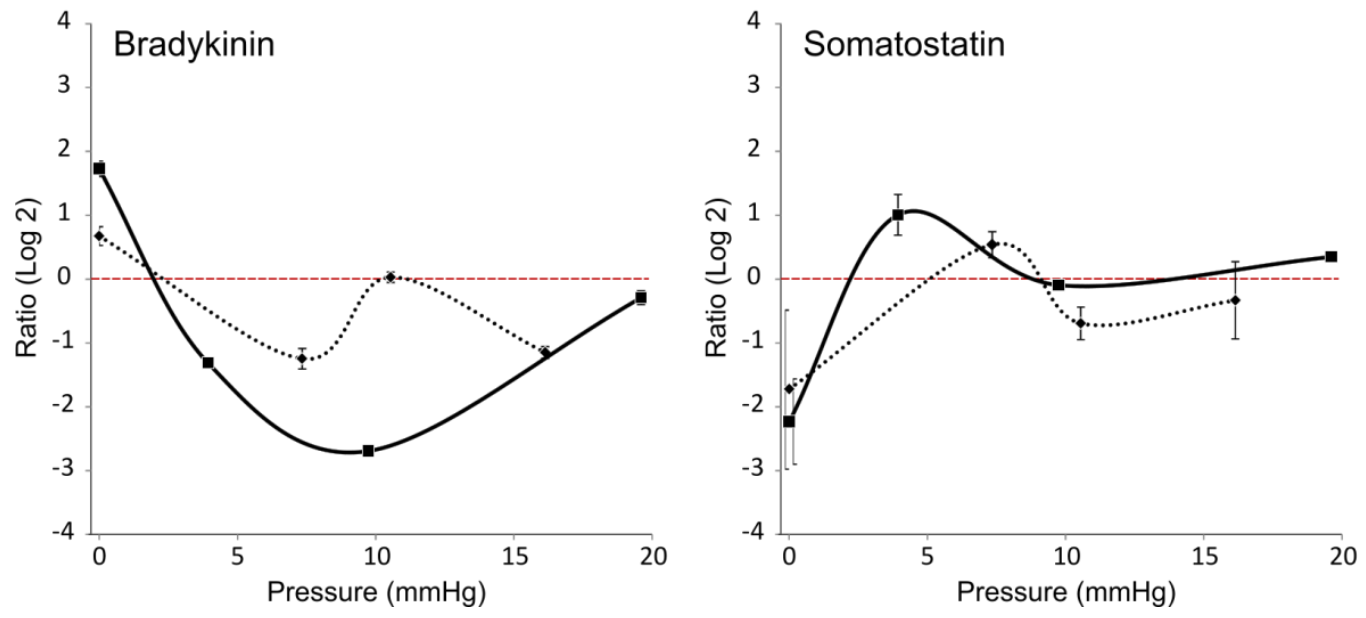

Page | 34 


\section{Figure 5}

a)

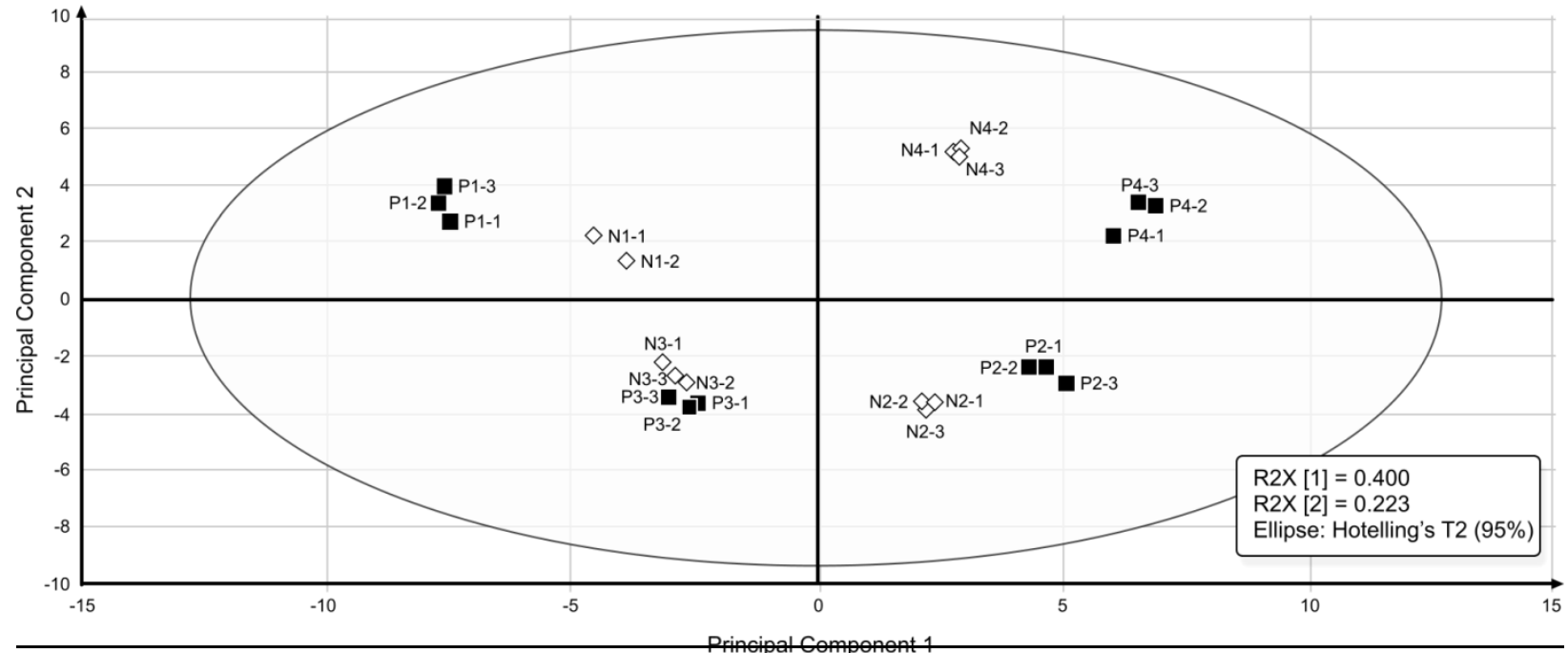

b)

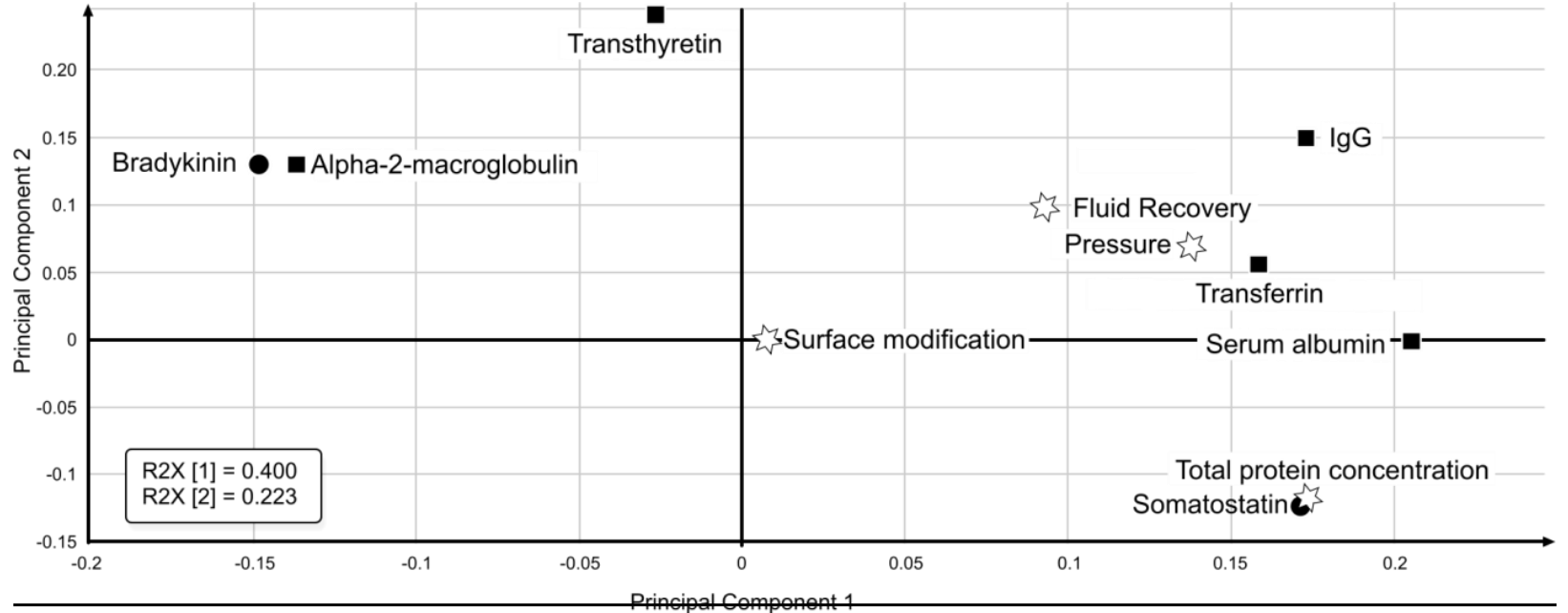

Page | 35 


\section{Supplementary Information}

Table S1. Experiments details of the Microdialysis sampling process and dialysates collection in this in vitro study.

\begin{tabular}{|c|c|c|c|c|}
\hline $\begin{array}{r}\text { Test set in } \\
\text { sequence }\end{array}$ & FR av. (\%) & $\begin{array}{r}\text { Chamber } \\
\text { Pressure } \\
\text { (torr) }\end{array}$ & $\begin{array}{l}\text { Test Duration } \\
\text { (min) }\end{array}$ & $\begin{array}{r}\text { Protein } \\
\text { standard }\end{array}$ \\
\hline Native 1 & $\begin{array}{l}94.75 \\
87.68 \\
85.14\end{array}$ & $\begin{array}{l}\text { Atm } \\
\text { Atm } \\
\text { Atm }\end{array}$ & $\begin{array}{l}140 \\
105 \\
126\end{array}$ & $\# 1$ \\
\hline Native 2 & $\begin{array}{l}111.71 \\
110.15 \\
109.86 \\
\end{array}$ & $\begin{array}{c}9.28 \\
10.29 \\
10.76 \\
\end{array}$ & $\begin{array}{c}100 \\
100 \\
90 \\
\end{array}$ & $\# 1$ \\
\hline Native 3 & $\begin{array}{r}97.14 \\
97.07 \\
101.52\end{array}$ & $\begin{array}{l}7.54 \\
5.07 \\
7.12\end{array}$ & $\begin{array}{l}125 \\
127 \\
120\end{array}$ & $\# 2$ \\
\hline Native 4 & $\begin{array}{l}121.13 \\
126.37 \\
121.62\end{array}$ & $\begin{array}{c}15.4 \\
17.13 \\
15.79\end{array}$ & $\begin{array}{c}110 \\
90 \\
90\end{array}$ & $\# 2$ \\
\hline Modified 1 & $\begin{array}{l}85.47 \\
88.41 \\
92.80\end{array}$ & $\begin{array}{l}\text { Atm } \\
\text { Atm } \\
\text { Atm }\end{array}$ & $\begin{array}{l}130 \\
120 \\
120\end{array}$ & $\# 3$ \\
\hline Modified 2 & $\begin{array}{l}87.82 \\
95.17 \\
90.61 \\
\end{array}$ & $\begin{array}{l}6.90 \\
3.42 \\
4.44 \\
\end{array}$ & $\begin{array}{l}115 \\
115 \\
115 \\
\end{array}$ & $\# 3$ \\
\hline Modified 3 & $\begin{array}{l}91.79 \\
97.53 \\
92.19\end{array}$ & $\begin{array}{r}14.34 \\
8.92 \\
10.53\end{array}$ & $\begin{array}{l}110 \\
120 \\
110\end{array}$ & $\# 4$ \\
\hline Modified 4 & $\begin{array}{l}109.52 \\
106.66 \\
105.03\end{array}$ & $\begin{array}{r}19.6 \\
18.91 \\
20.2\end{array}$ & $\begin{array}{l}100 \\
90 \\
100\end{array}$ & $\# 4$ \\
\hline
\end{tabular}

Page $\mid 36$ 